\title{
ARTERIOVENOUS ANEURYSM ON THE PULMONARY ARTERY SIMULATING PATENT DUCTUS ARTERIOSUS BOTALLI
}

\author{
BY \\ GUNNAR BIÖRCK AND CLARENCE CRAFOORD \\ Stockholm, Sweden*
}

The diagnosis of patent ductus arteriosus Botalli is usually established by the simultaneous finding of a continuous murmur over the pulmonary area, frequently accompanied by a thrill, and prominence of the pulmonary artery together with "hilar dance" at fluoroscopy. Right heart catheterization has made possible a closer study of the haemodynamic and circulatory effects of the arteriovenous shunt in cases of patent ductus and other congenital heart lesions, and will thus increase the precision of the diagnosis. A diagnostic mistake therefore seems unlikely, provided these investigations are undertaken. In this paper, however, we report a case in which there was a continuous murmur over the pulmonary area, confirmed by phonocardiogram, and where the fluoroscopy and radiograph were judged to be fairly characteristic of a patent ductus arteriosus by the radiologist who studies most of the patients with congenital heart disease brought to the clinics of Nylin and Crafoord. Right heart catheterization was not performed, but it is clear from the operative findings that it would have given no aid in establishing the diagnosis before operation. Instead of a patent ductus, the operation revealed an abnormal artery, originating from the base of the heart and winding along the wall of the pulmonary artery, with which it communicated through an aneurysmal dilatation. This imitated the symptoms and signs, of a patent ductus in the production and propagation of murmurs, and also, to a certain extent, radiographically. As there was an arteriovenous shunt from the arterial to the venous side of the heart, it would probably not have been possible by blood gas analysis of samples taken by right heart catheterization to deduce in detail the nature of the shunt. However, the diagnostic error was only an anatomical one ; operation would equally have been indicated, even had the true nature of the abnormality been suspected.

Although there have been some recent articles about pulmonary aneurysm, and also about abnormalities of the coronary arteries, we have not been able to find any report of a congenital communication between the coronary and the pulmonary arteries. It is evident from the studies of d'Aunoy and von Hamm (1934), Boyd and McGavack (1939), Nixon (1944), and Holmes (1944) that there are real aneurysms of the pulmonary artery and that these are sometimes com-

*From the Medical Clinic II, Physician-in-chief, Prof. G. Nylin ; and the Surgical Clinic I, Surgeon-in-chief, Dr. C. Crafoord; Sabbatsberg Hospital, Stockholm, Sweden. 
bined with congenital lesions, particularly patent ductus. In these articles, covering the medical literature from 1833 up to the present time, there is no reference to cases of the type described in this report. The only arteriovenous aneurysms mentioned were a communication between the pulmonary artery and one pulmonary vein as a result of a gunshot wound (case 83 in the review by d'Aunoy and von Hamm) and Halpert's case mentioned below. Keys and Shapiro (1943) and Touroff (1943), discussing patent ductus, make no mention of any abnormality of the present type. Touroff (1943) states that in one of his cases a continuous murmur persisted after division of the ductus, and that it disappeared when he pressed upon the pulmonary artery; he therefore believes that dilatation of the pulmonary artery may cause a continuous murmur. This is not agreed to by Keys (1943), who thinks that a continuous murmur must mean a persisting arteriovenous communication.

As regards abnormalities of the coronary vessels, it is well known that a coronary artery sometimes originates in the pulmonary artery instead of the aorta. This is a dangerous condition, most often resulting in severe myocardial damage and not compatible with more than a brief span of life, although exceptions are known (H. Sprague, personal communication). The situation in the present case was apparently the reverse: a coronary vessel communicating through an aberrant branch with the pulmonary artery, producing an arteriovenous aneurysm. Rigdon and Vandergriff (1943) have recently reviewed the literature on coronary aneurysms. None of their cases is said to have been of the arteriovenous type. Halpert (1930) has reported one case of communication between a coronary artery and the coronary sinus. This is the only case somewhat similar to ours that we have encountered in the literature.

\section{CASE REPORT}

The patient, a boy born in 1931, had no family history of cardiovascular disease. As long as he remembers he has been a little handicapped in playing and running with his fellows. During the last two years he has been unable to do gymnastics or play football on account of dyspnoea shortly after the beginning of the exercise. He was observed by a local physician in 1938, when a presystolic murmur was said to have been heard, especially over the pulmonar' area. This seems to have been accentuated in 1940, and in 1941 a whistling systolic and diastolic murmur with the same localization was noted. In January, 1945 , on two occasions when skiing he became pale, with severe dyspnoea and palpitations. In April, 1946, the boy was more tired than previously. A continuous murmur over the pulmonary area was heard. The blood pressure was 115/70. Electrocardiogram and radiography of the heart were considered normal, although at fluoroscopy the right auricle was seen to pulsate strongly. A congenital heart lesion was suspected, and in August, 1946, the patient was referred to the Sabbatsberg Hospital for more thorough study, and eventually operation.

Physical Examination.-The boy was of average physical development for his age, although somewhat slender and pale. With the exception of the heart, nothing abnormal was found on routine examination. There was no dyspnoea at rest, no cyanosis, and no oedema. The liver was not enlarged. There was slight fullness, but no abnormal pulsation 
in the praecordium. The heart's apex beat was felt in the fifth intercostal space, slightly to the left of the nipple line. No thrill was noted. Over the pulmonary area a systolicdiastolic murmur of the continuous type was heard, with its maximum in the first intercostal space, $4 \mathrm{~cm}$. to the left of the middle of the sternum. The auscultatory findings were more pronounced than those registered on the phonocardiogram. The heart rhythm was regular. Blood pressure in the left arm was $135 / 80 \mathrm{~mm} . \mathrm{Hg}$, in the right arm $140 / 80$, in the lett leg $165 / 95$, and in the right leg $160 / 95$. The venous pressure, measured in the antecubital vein with the patient recumbent, was $8 \mathrm{~cm}$. above the level of the posterior axillary line. The arm-tongue circulation time, measured with decholin, was 8-16-21 seconds.* Radiography showed the left border of the heart shadow to be somewhat rounded; the pulmonary artery was slightly bulging, and along the left border the pulsations were exaggerated. There were simultaneous strong pulsations of the hilar vessels (hilar dance). Measured by means of the kymograph, the range of pulsation along the left heart border and the aorta was $5 \mathrm{~mm}$., and along the pulmonary artery $4 \mathrm{~mm}$. The heart volume, estimated by the method of Kahlstorf (1932), was $580 \mathrm{ml}$.-i.e., $310 \mathrm{ml}$. per square metre of body surface (Plate Ia). The electrocardiogram was normal, with no axis deviation (Plate $\mathrm{Va}$ ). The anoxaemia test with 9 per cent oxygen for $10 \mathrm{~min}$. was negative. The cardio-respiratory functional test of Nylin (1933 and 1938) showed a normal response to heavy exercise. Oscillography in arms and legs by the method of Ejrup (1944) was normal. Phonocardiograms demonstrated a continuous murmur over the pulmonary area (Plate II $a$ ). The laboratory findings were all normal. The Wassermann test was negative.

Although it was noted that the murmur was perhaps somewhat different in quality from that usually heard in cases of patent ductus, the radiographic and the phonocardiographic findings made the diagnosis of a patent ductus so probable that thoracotomy was decided upon.

OperATION (July 22, 1946). - The chest was opened by a postero-lateral incision by the method of Crafoord, with removal of the fifth rib. The left lung and the heart were normal. In the region of the ductus arteriosus no thrill was palpable. Over the main stem of the pulmonary artery, one inch from the pulmonary valves, a distinct continuous thrill was feit. The region of a ductus arteriosus was dissected. A cord without visible lumen was found, doubly ligated, and divided. Thereafter, the thrill over the pulmonary artery was felt as before. The pericardium therefore was opened. An abnormal artery as thick as a slate pencil was found (Plate VI). As the drawing shows, the artery originated in the groove between the left auricular appendix and the conus arteriosus. The area from which the artery arose was not dissected, but it probably originated in the left coronary artery. After having crossed the pulmonary artery at right angles to its longitudinal axis up to the middle of its anterior surface, the artery suddenly bulged into an aneurysm-like sac the size of a pea. As shown in the drawing, the artery continued from this aneurysm and finally vanished into the mediastinal tissue on the outside of the pericardium. The maximum of the continuous thrill was localized to the area of the aneurysm, and auscultation with a sterile stethoscope revealed a continuous murmur similar in character to that heard before operation but somewhat different from that heard in ordinary cases of patent ductus. Round the abnormal artery centrally to the aneurysm a silk ligature was applied and tightened. As there was no reaction from the heart during three or four minutes of observation, the silk ligature was tied. On auscultation the murmur had now much decreased. Another ligature was now applied peripherally to the aneurysm and tied. Thereafter, the continuous murmur disappeared, although a short systolic murmur over the base of the pulmonary artery was still heard. The pericardium and the chest wall were then closed without drainage. sensation.

*These times refer to the beginning, the maximal intensity, and the end of the taste 
An electrocardiogram and a phonocardiogram (only one frequency range, unfortunately) were taken the day after the operation. The electrocardiogram (Plate $\mathrm{V} b$ ) shows an elevation of the S-T segment as compared with the tracings before the operation and later on. This probably indicates myocardial ischaemia on the epicardial surface, due to the pericardial incision and the operative procedure at the heart base. The phonocardiogram shows the disappearance of the previous continuous murmur (Plate $\mathbf{I} b$ ).

The post-operative course was uneventful. Two weeks after the operation a short, moderately harsh systolic murmur was heard, maximal in the third intercostal space to the left close to the sternum. No diastolic murmur was heard. There were no other remarkable findings. The radiograph is shown in Plate $\mathrm{I} b$. The electrocardiogram was again normal, and similar to that before the operation. The phonocardiogram (Plate III) gave some evidence of a slight systolic murmur, but nothing else.

The patient was re-examined in November, 1946. Since the operation he had felt very much improved. He had no dyspnoea on moderate exertion. Physical examination revealed the same pallor and slenderness as before. There were no signs of decompensation. All over the praecordium there was a moderately harsh systolic murmur, with its maximum in the third intercostal space, close to the sternum. The second pulmonary sound was accentuated. No diastolic murmur was heard. A soft murmur was sometimes heard in diastole, but was in all probability propagated from the lungs. The electrocardiogram showed some sinus arrhythmia, but was otherwise similar to the previous ones. The anoxaemia test was negative. The response to the heavy functional test of Nylin was within normal limits. The radiograph of the heart was normal (Plate Ic). The phonocardiogram (Plate IV) showed a systolic but no diastolic murmur.

\section{SUMMARY}

A case is reported in which the pre-operative diagnosis of a patent ductus arteriosus was made on account of a continuous murmur and a fairly typical radiograph. Operation revealed as the source of the murmur, instead of a patent ductus, an arteriovenous communication between an aneurysm of an aberrant branch of a coronary artery and the pulmonary artery. After double ligation of the abnormal vessel, the murmur disappeared. The post-operative course was uneventful and the patient improved considerably afterwards.

\section{REFERENCES}

Bohm, E. (1941). Nord. Med., 9, 380.

Boyd, L. J., and McGavack, Th. H. (1939). Amer. Heart J., 18, 562.

Brown, J. W. (1939). Congenital Heart Disease. London.

Chipps, H. D. (1942). Amer. J. med. Sci., 204, 246.

Crafoord, C., Mannheimer, E., and Wiklund, Th. (1944). Acta chir. scand., 91, 97.

d'Aunoy, R., and Hamm, E. v. (1934). J. Path. Bact., 38, 39.

Ejrup, B. (1944). Nord. Med., 23, 1770.

Halpert, B. (1930). Heart, 15, 129.

Henschen, S. E. (1906). Samml. Klin. Vortr., No. 422-3.

Holmes, H. R. (1944). Brit. J. Radiol., 17, 312.

Kahlstorf, A. (1932). Fortschr. Roentgenstr., 45, 123.

Keys, A., and Shapiro, M. J. (1943). Amer. Heart J., 25, 158.

Nixon, J.' W. (1944). J. thorac. Surg., 13, 513 .

Nylin, G. (1933). Acta med. scand., Supp. 52.

Nylin, G. (1938). Acta med. scand., Supp. 93.

Posselt, A. (1909). Ergebn. Allg. Pathologie Path. Anatomie, 13, 298.

Rigdon, R. H., and Vandergriff, H. (1943). Amer. J. Surg., 61, 407.

Touroff, A. S. W. (1943). Amer. Heart J., 25, 187.

White, P. D. (1944). Heart Disease. New York. 


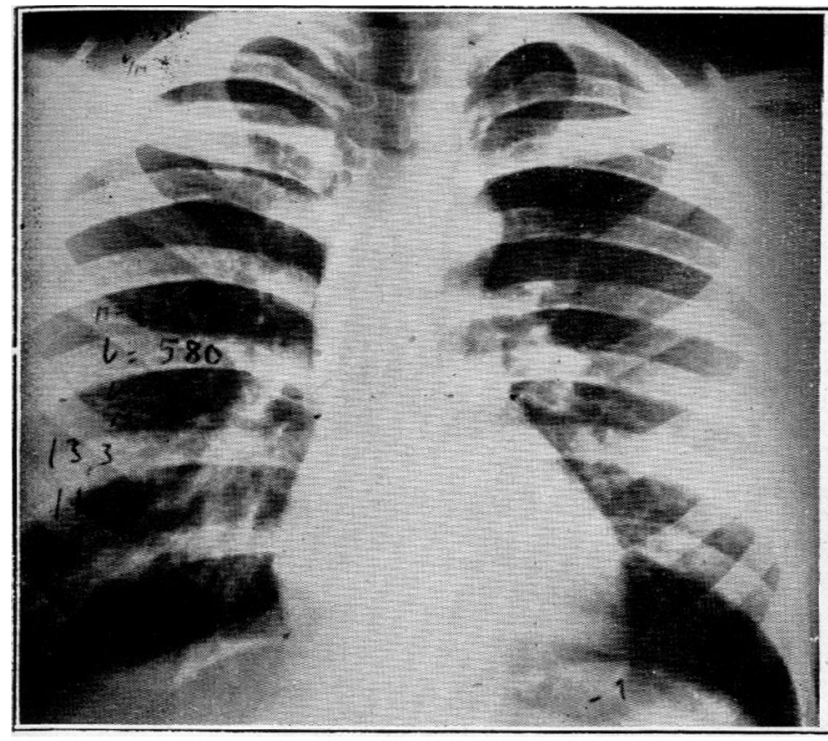

$a$

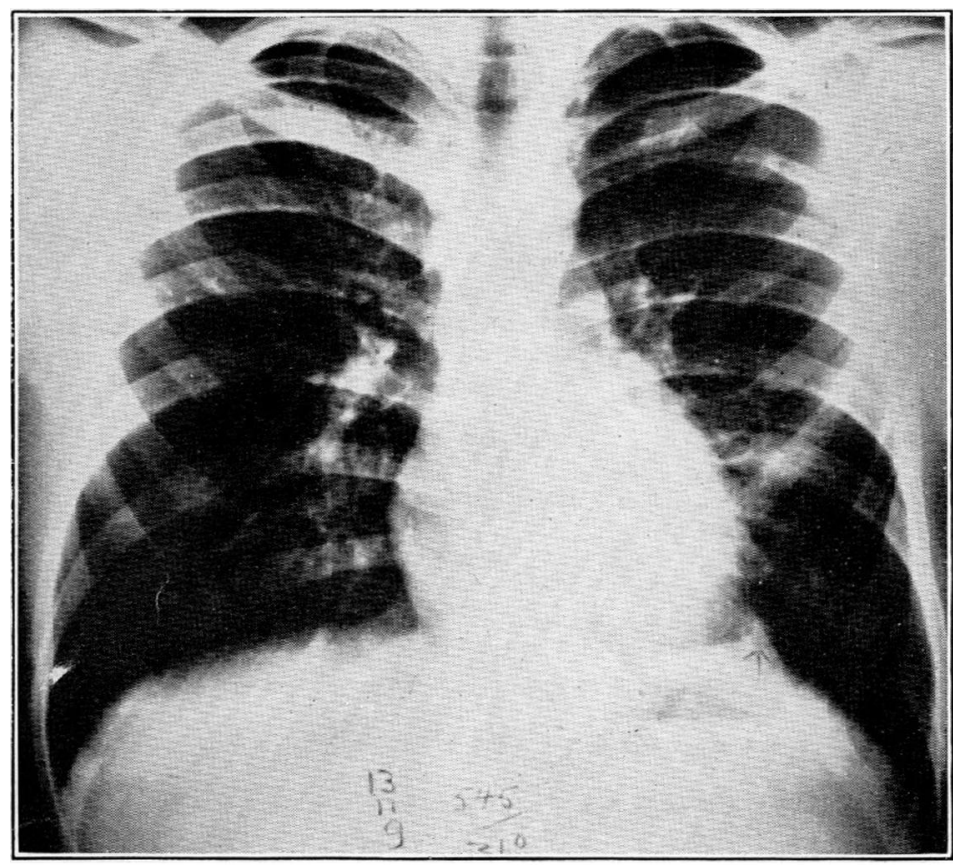

c

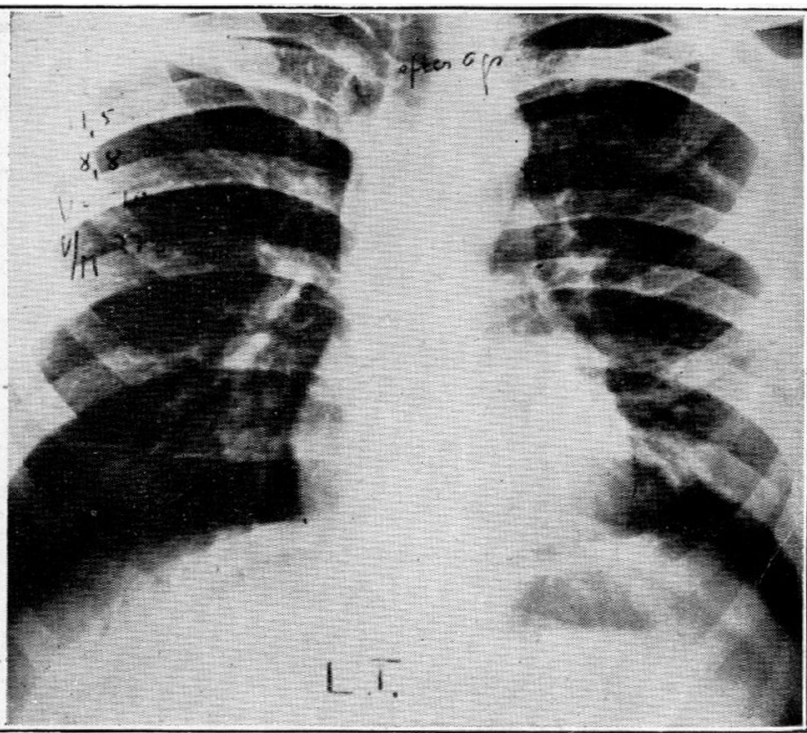

b
Plate I.-Radiographs 음 of the heart $(a)$ before operation; $(b) \frac{D}{0}$ two weeks after operation ; $(c)$ four $N$ months after opera- $\sigma$ tion. 

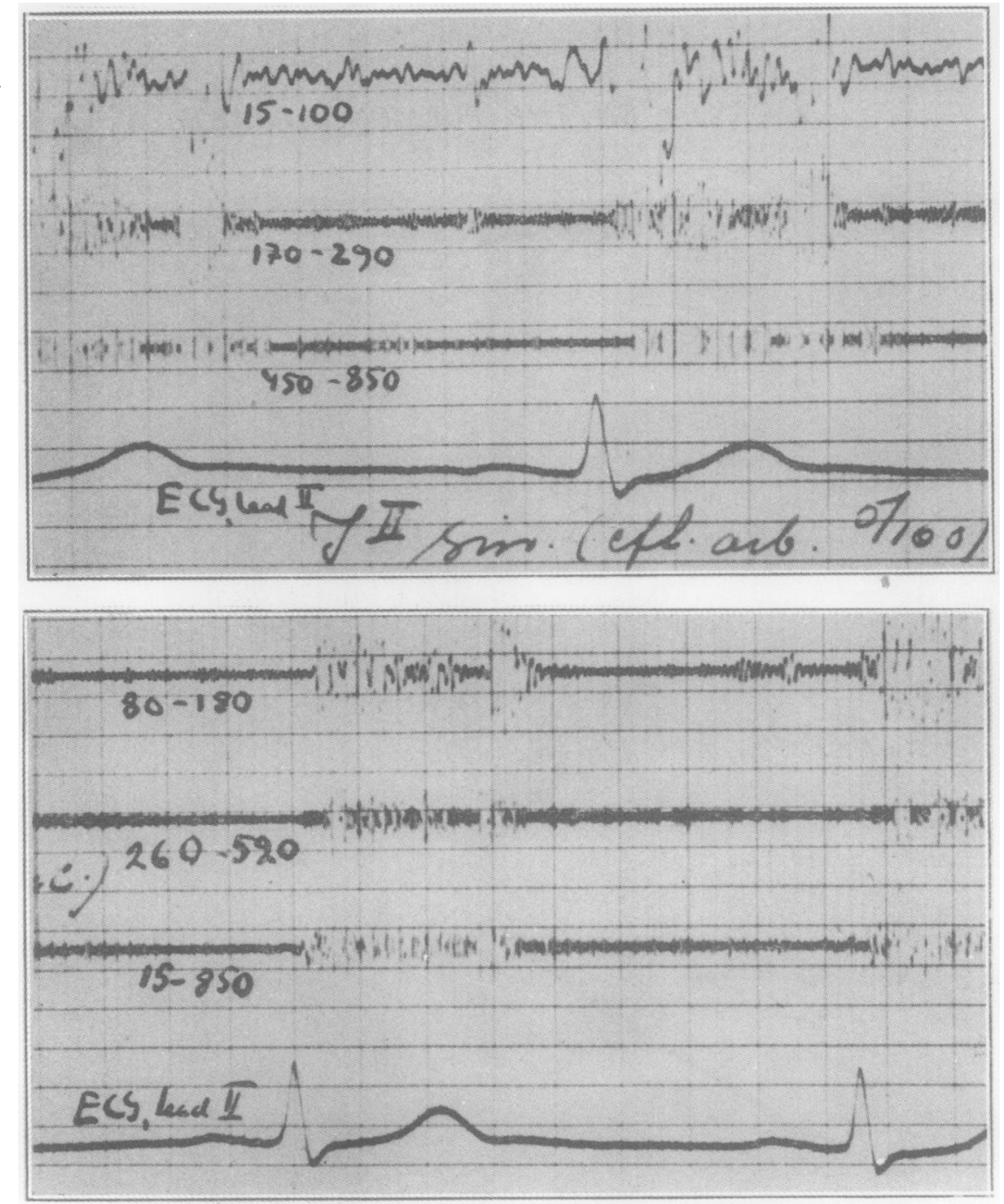

PLATE Ila.-Phonocardiogram before operation, with lead II of electrocardiogram. The figures below each tracing represent the frequency range in cycles per second.

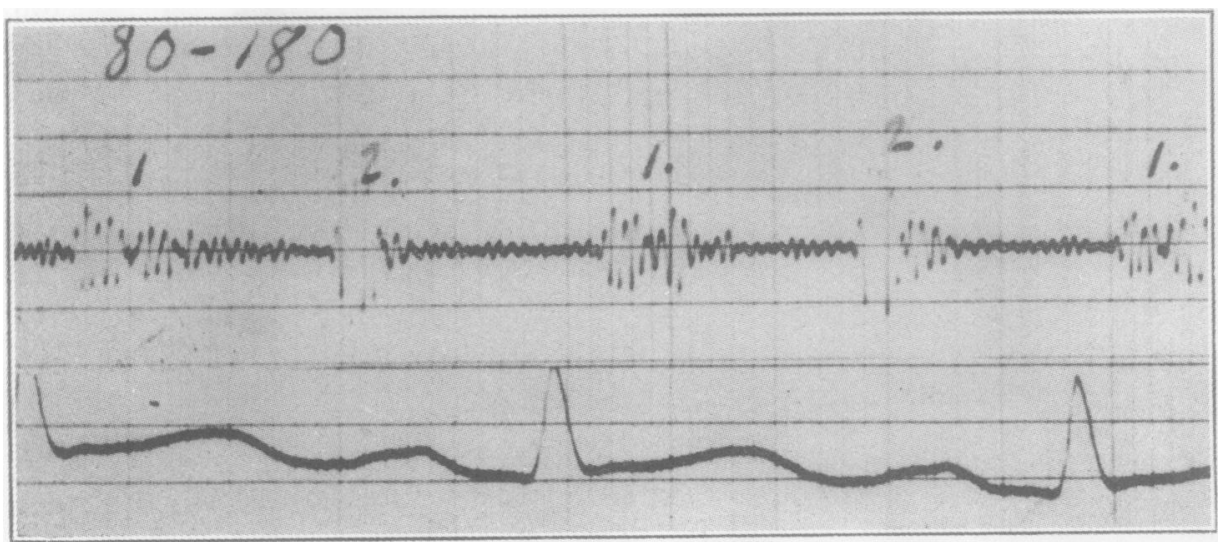

Plate Il b.-Phonocardiogram one day after operation. 


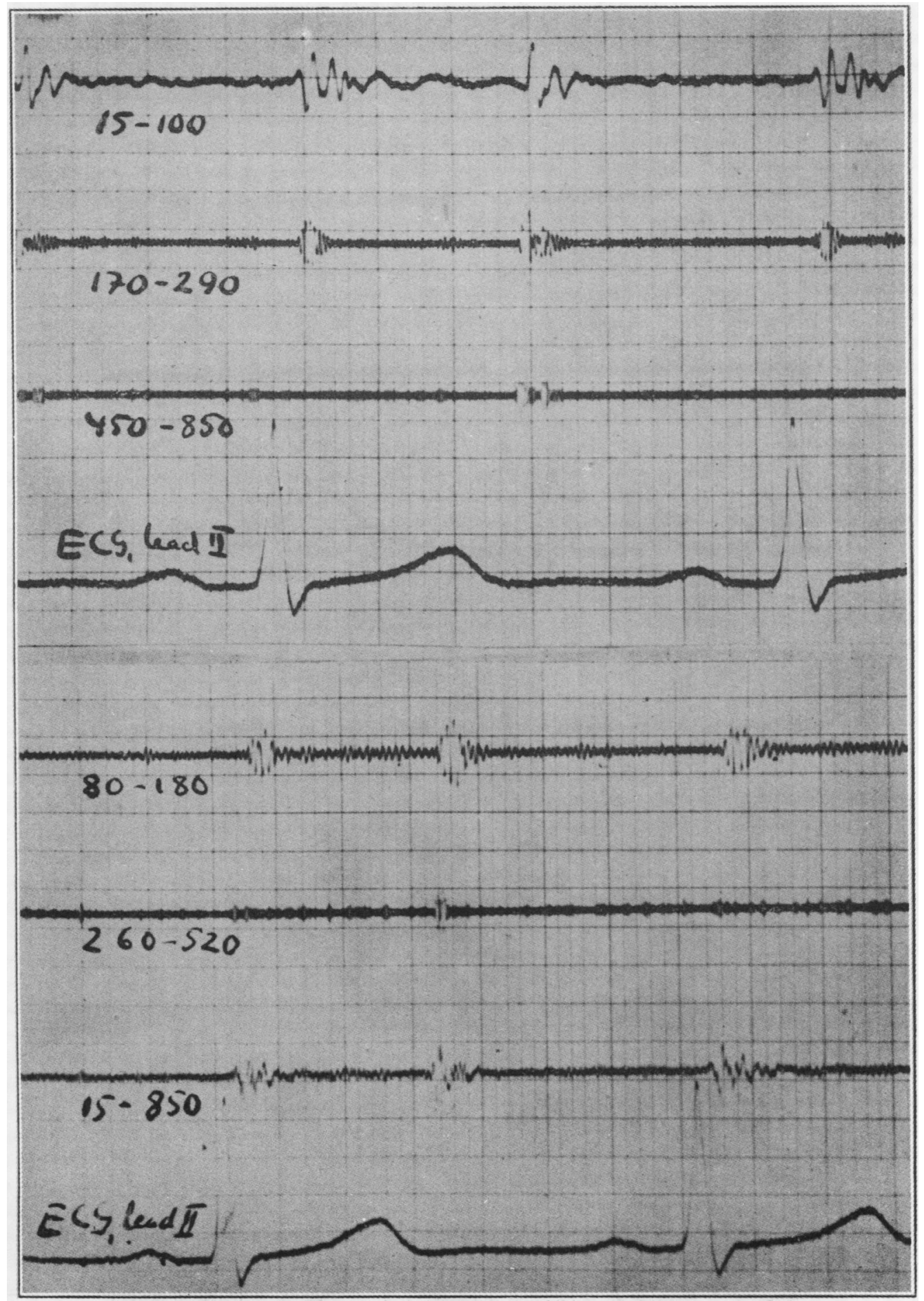

Plate III.-Phonocardiogram two weeks after operation. 


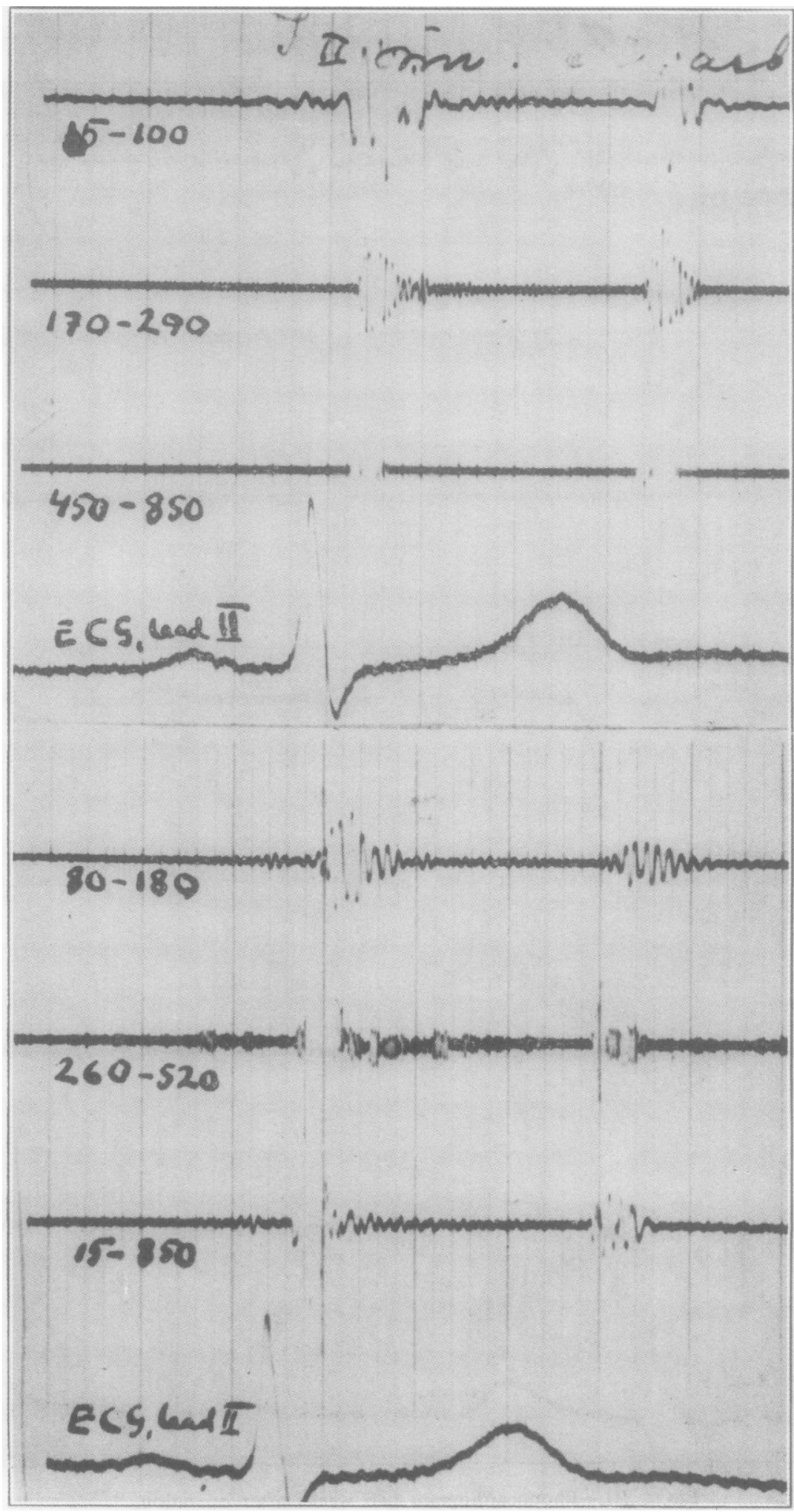

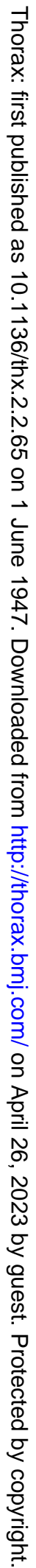

PLATE IV.-Phonocardiogram four months after operation. 


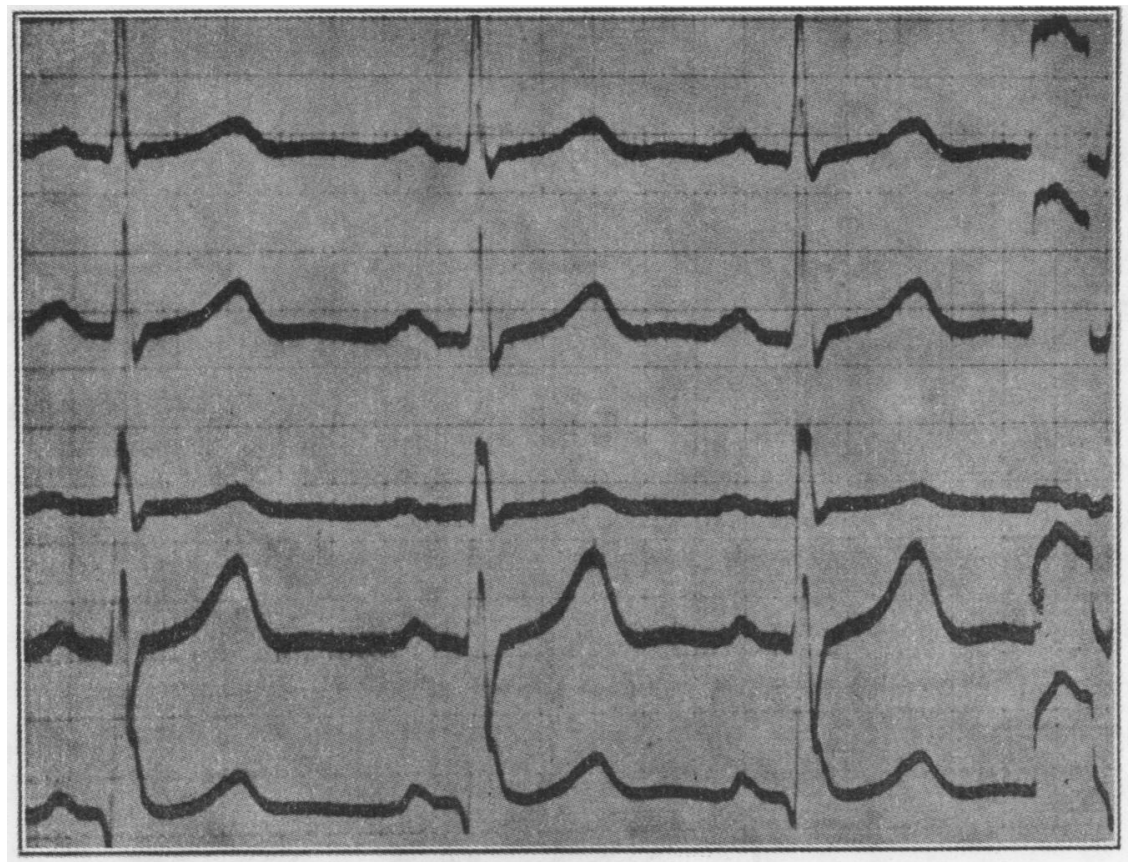

$a$

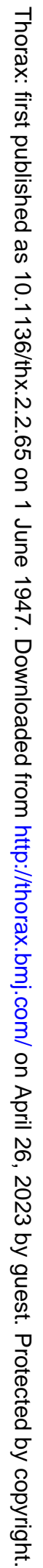

Plate V.-Electrocardiograms (a) before operation, $(b)$ one day after operation. (The 4th and 5th leads in Plate Va are anterior and posterior chest leads.) 


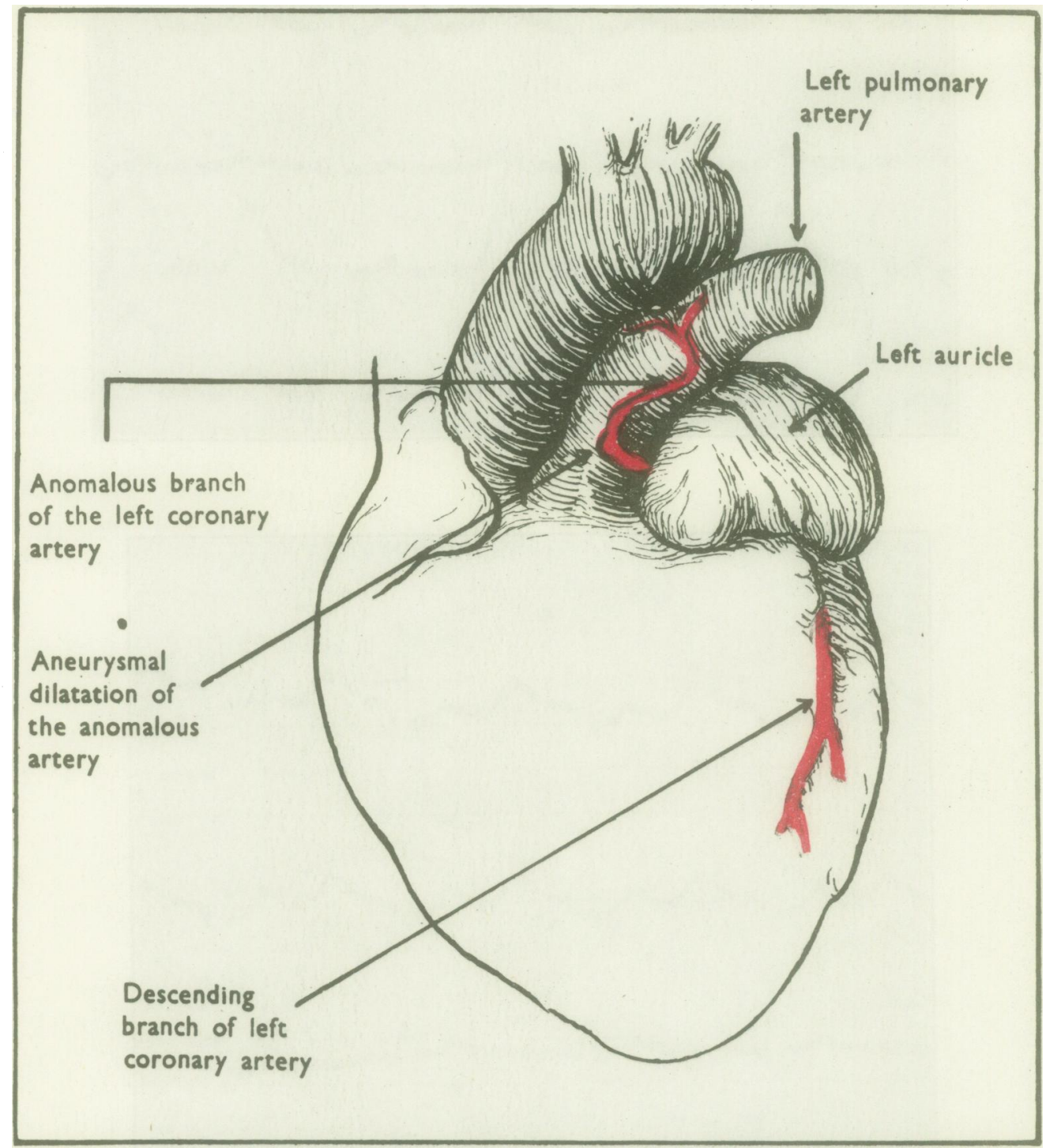

PLATE VI.-Drawing of the heart and the abnormal coronary branch, made at the operation. 


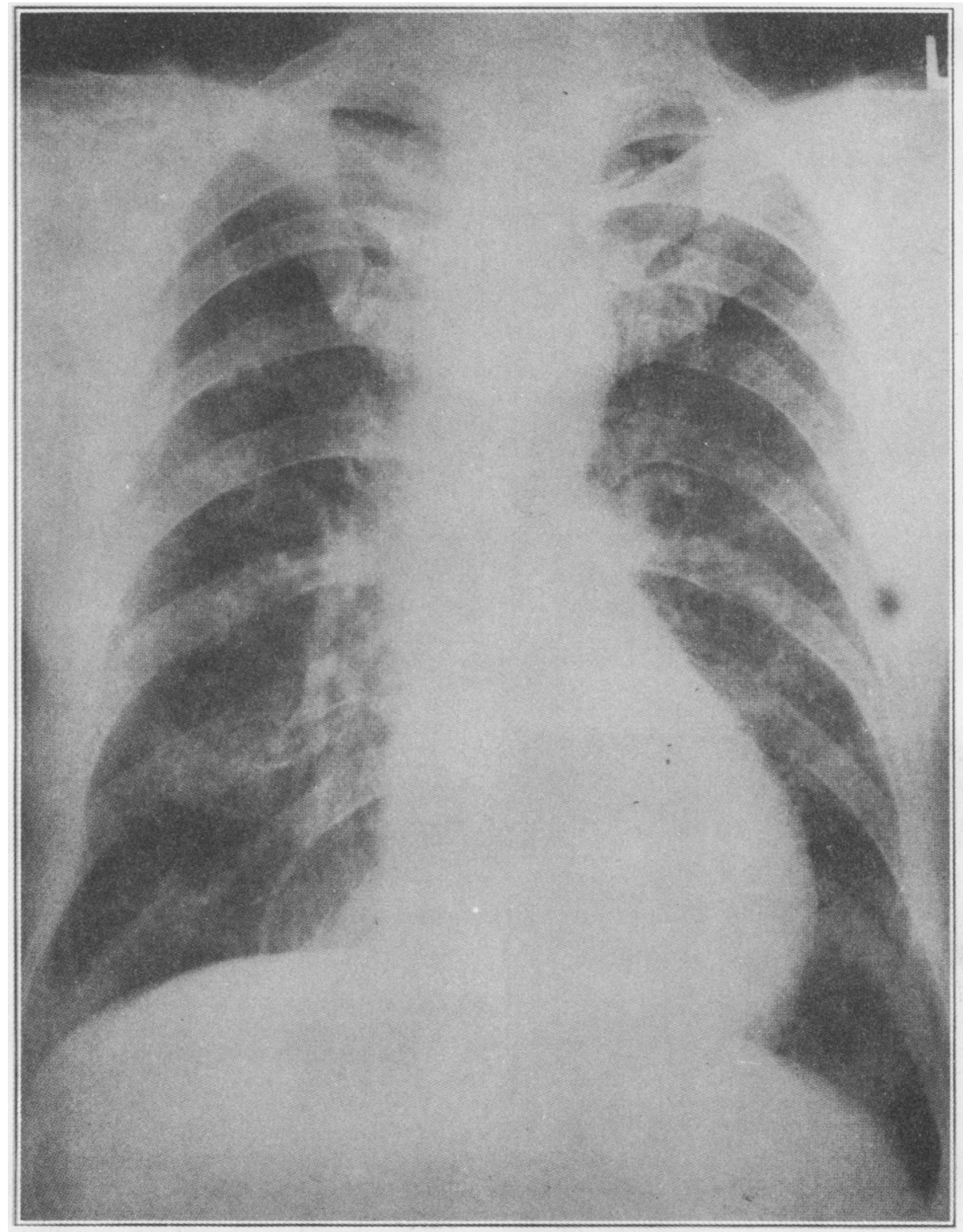

Plate VII.-Man aged 38, vanadium worker for six years, complaining of dyspnoea and cough. Radiograph shows reticulation. 


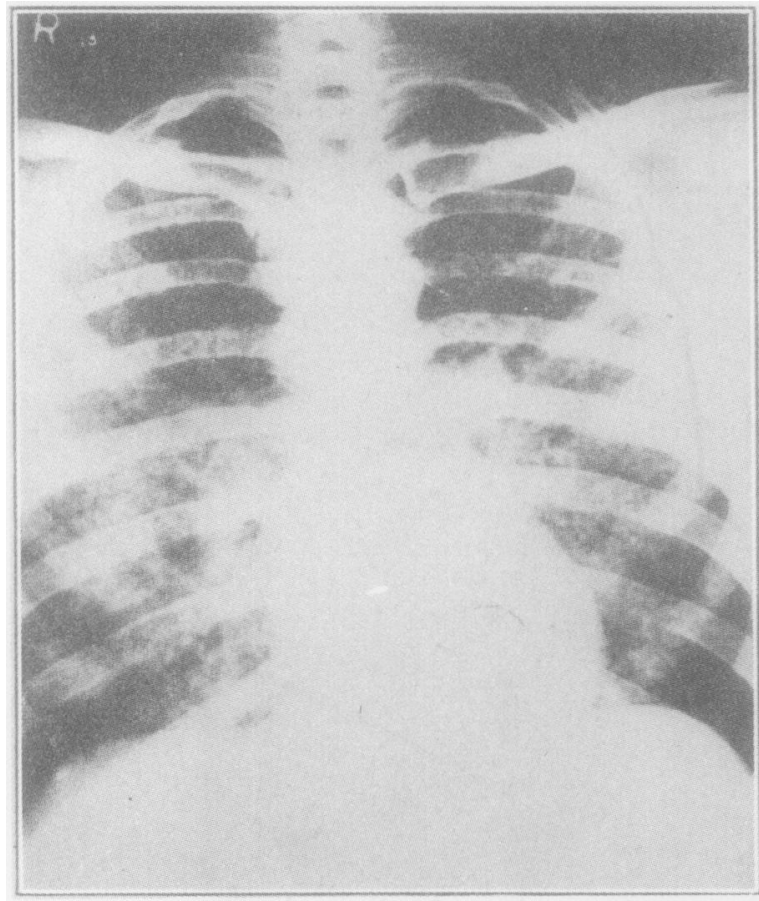

Plate A

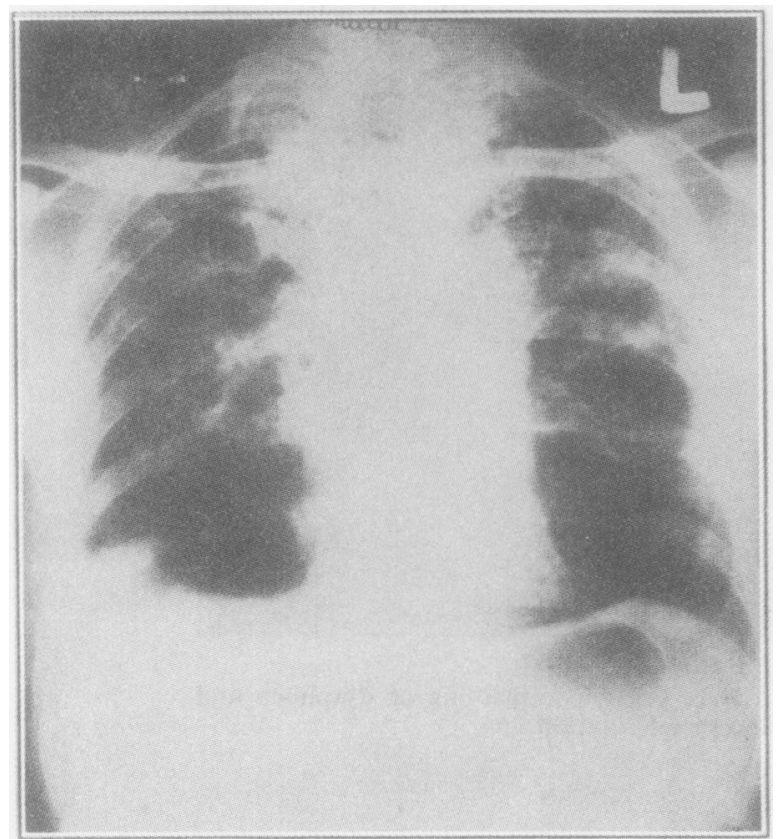

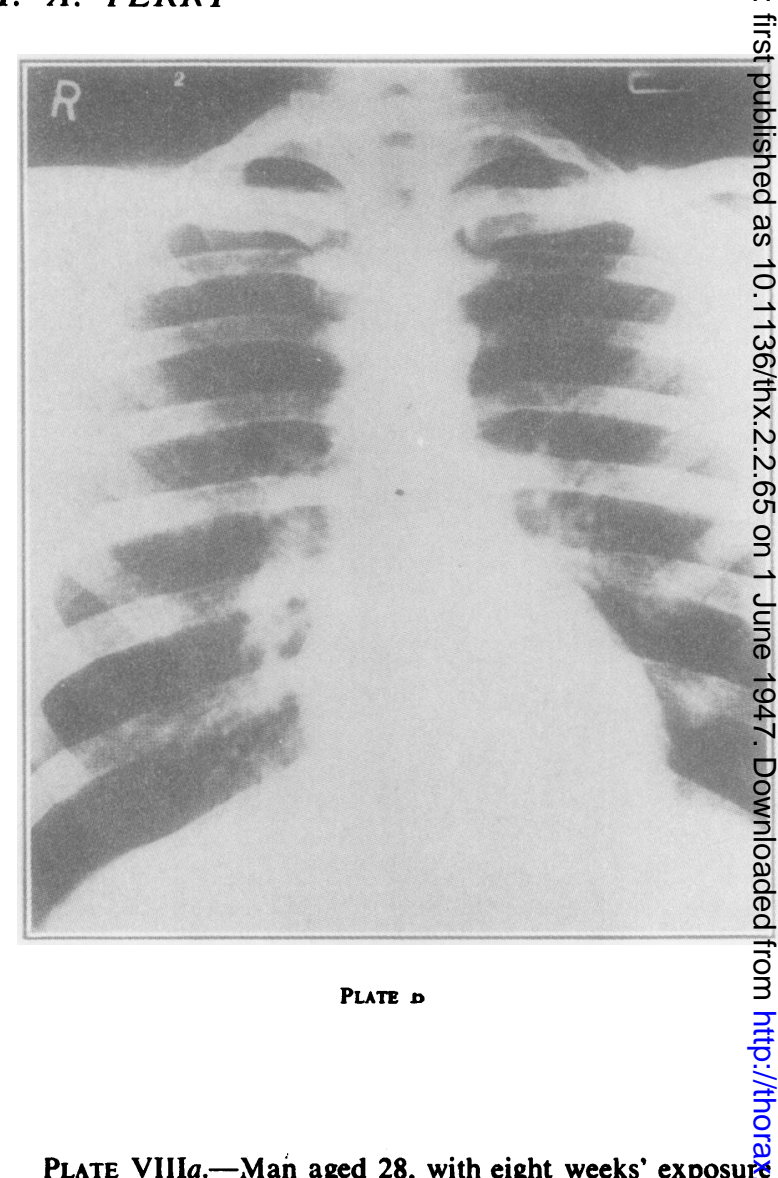

Plate VIIIa.-Man aged 28, with eight weeks' exposure to bagasse, complaining of cough, purulent sputuris fever and haemoptys.s. (Dr. W. E. Lloyd's patien

\section{을}

Plate VIII $b$.-The same patient two months later. further photograph three years afterwards showe that the chest remained clear.

$N$
N
U
O

Plate VIIIc.-Man aged 38, two years after six weeks exposure to bagasse, complained of shortness breath and cough with scanty sputum. Necropsy showed bronchiolectasis and a much thickene而 pleura. 


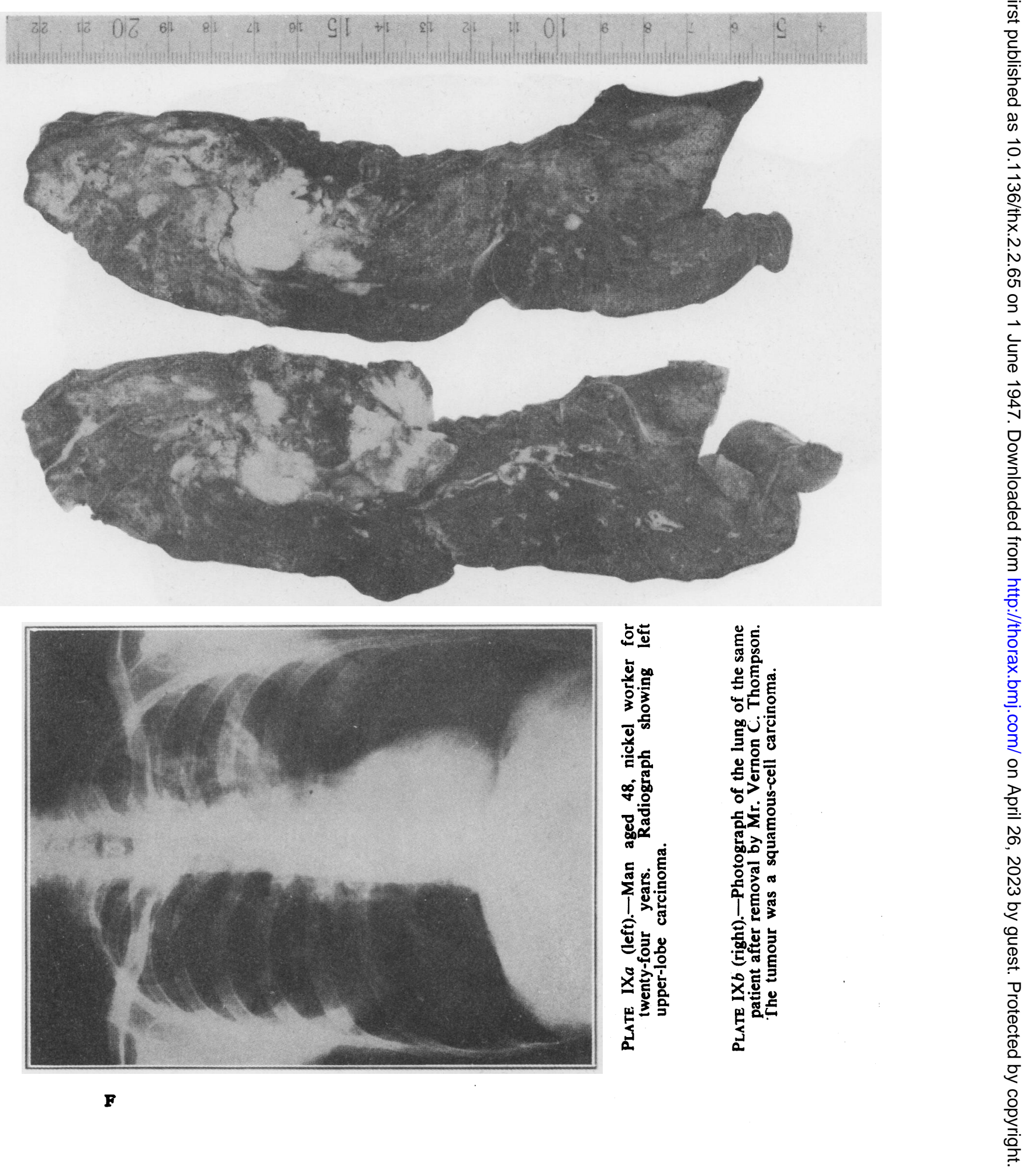



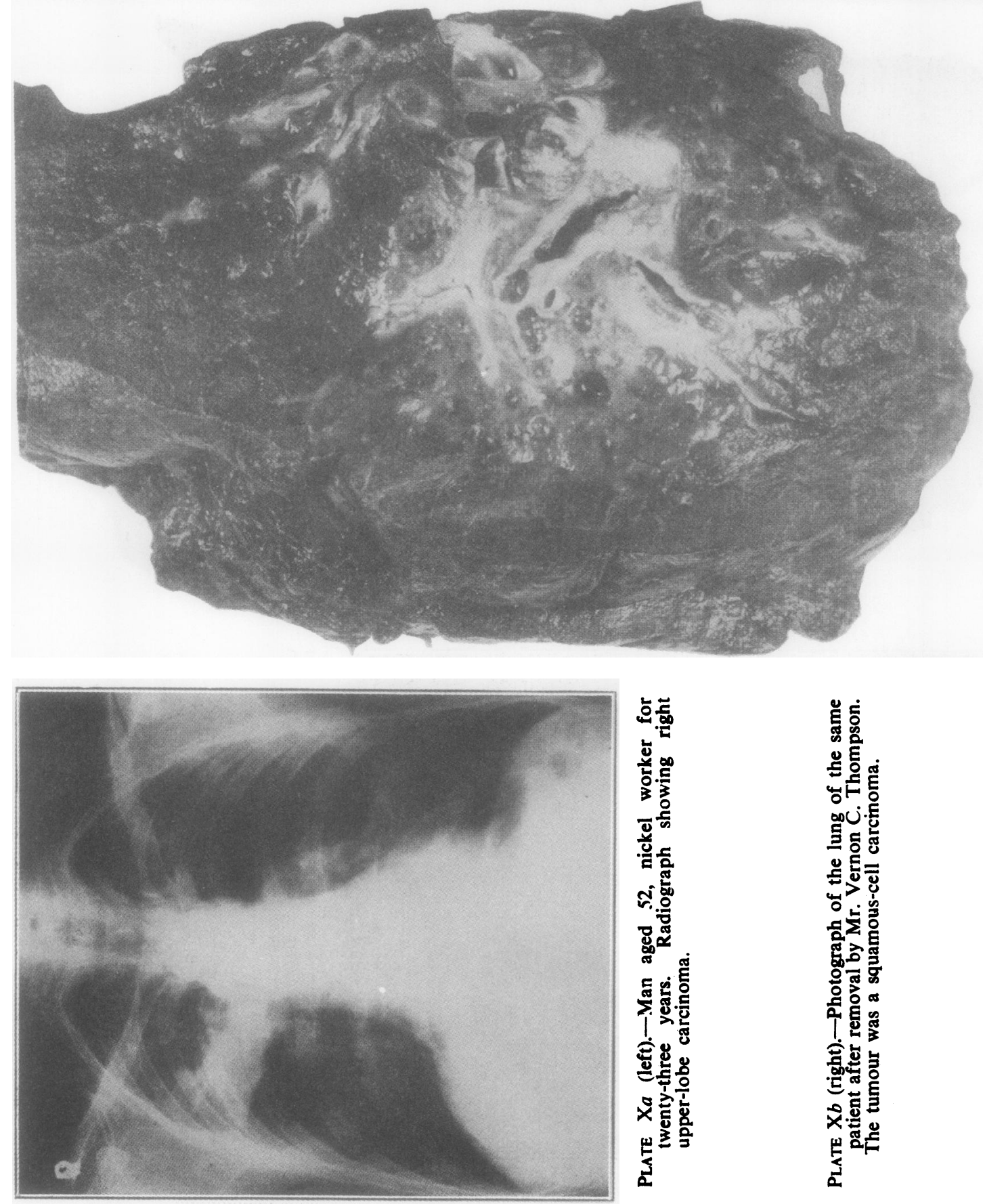


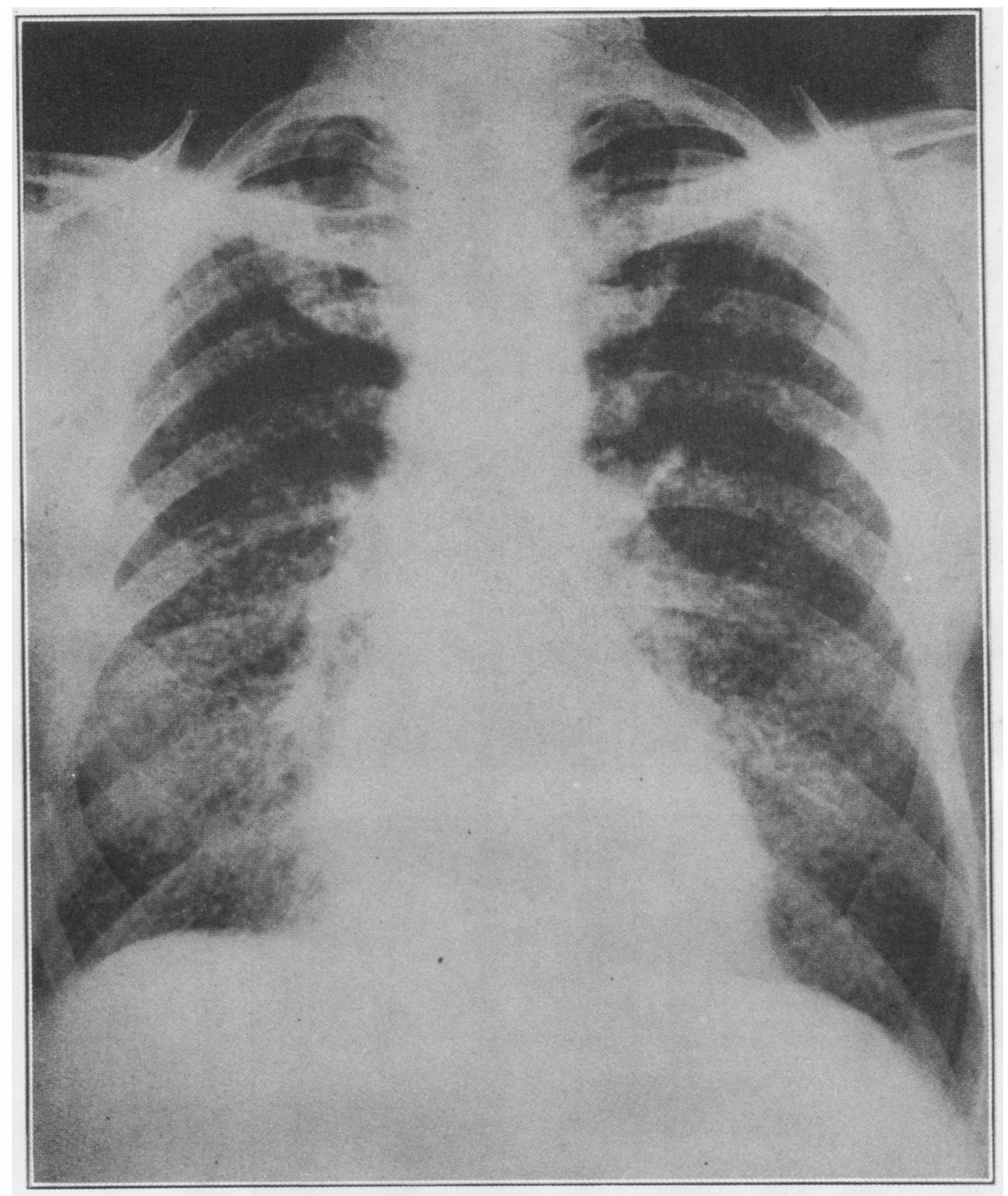

Plate XI.-Man aged 60, electric arc welder in steel foundry for twenty-one years. He had no symptoms. 

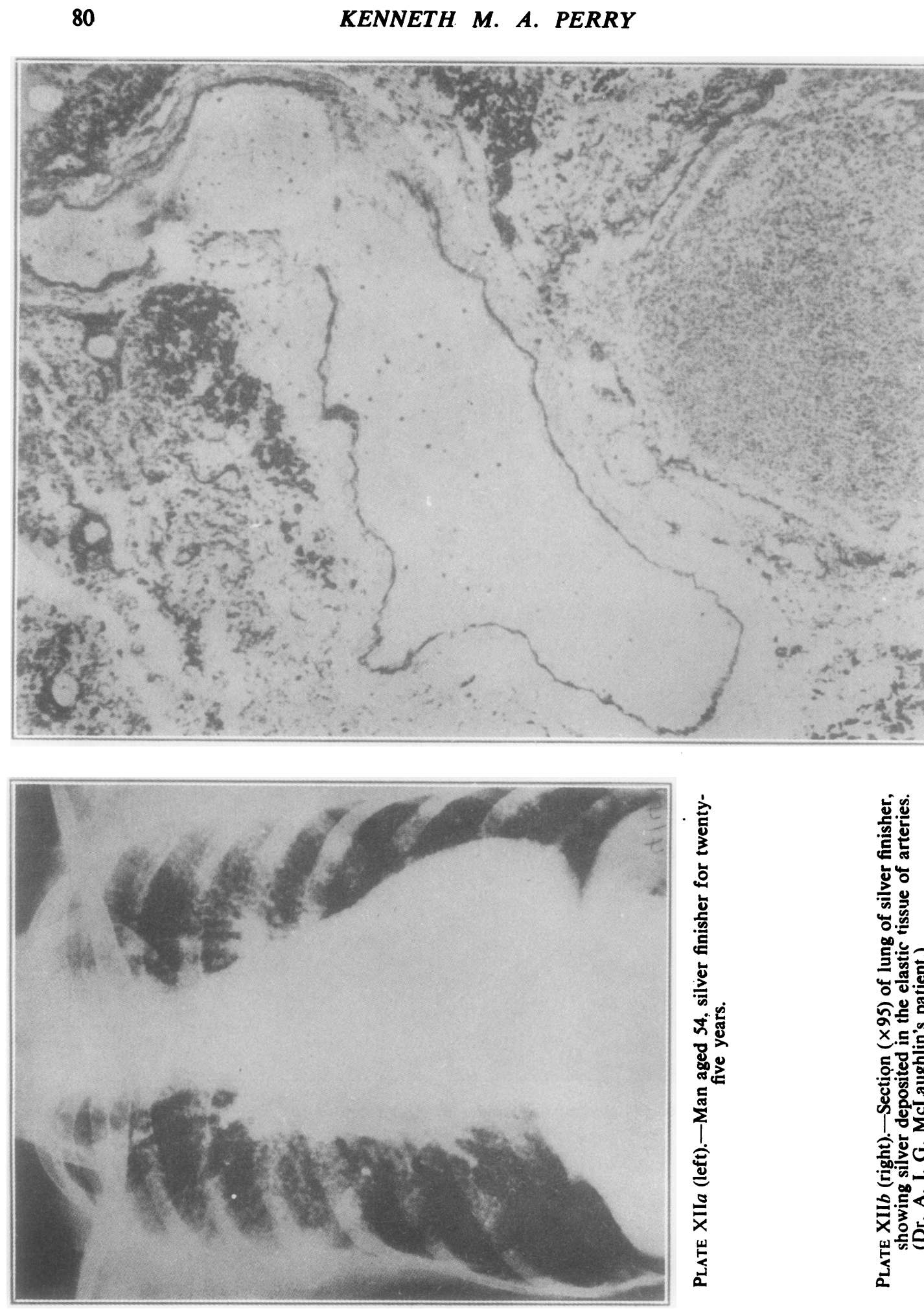

氖.

过

产产

㝕昰

氜氙 N

กิ 용

⿵人一

ㅈ..․ㅡ 웅

도ㅇㅝㅛ

ช⿺辶大

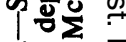

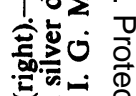

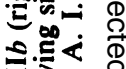

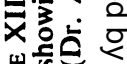

䋇

送 

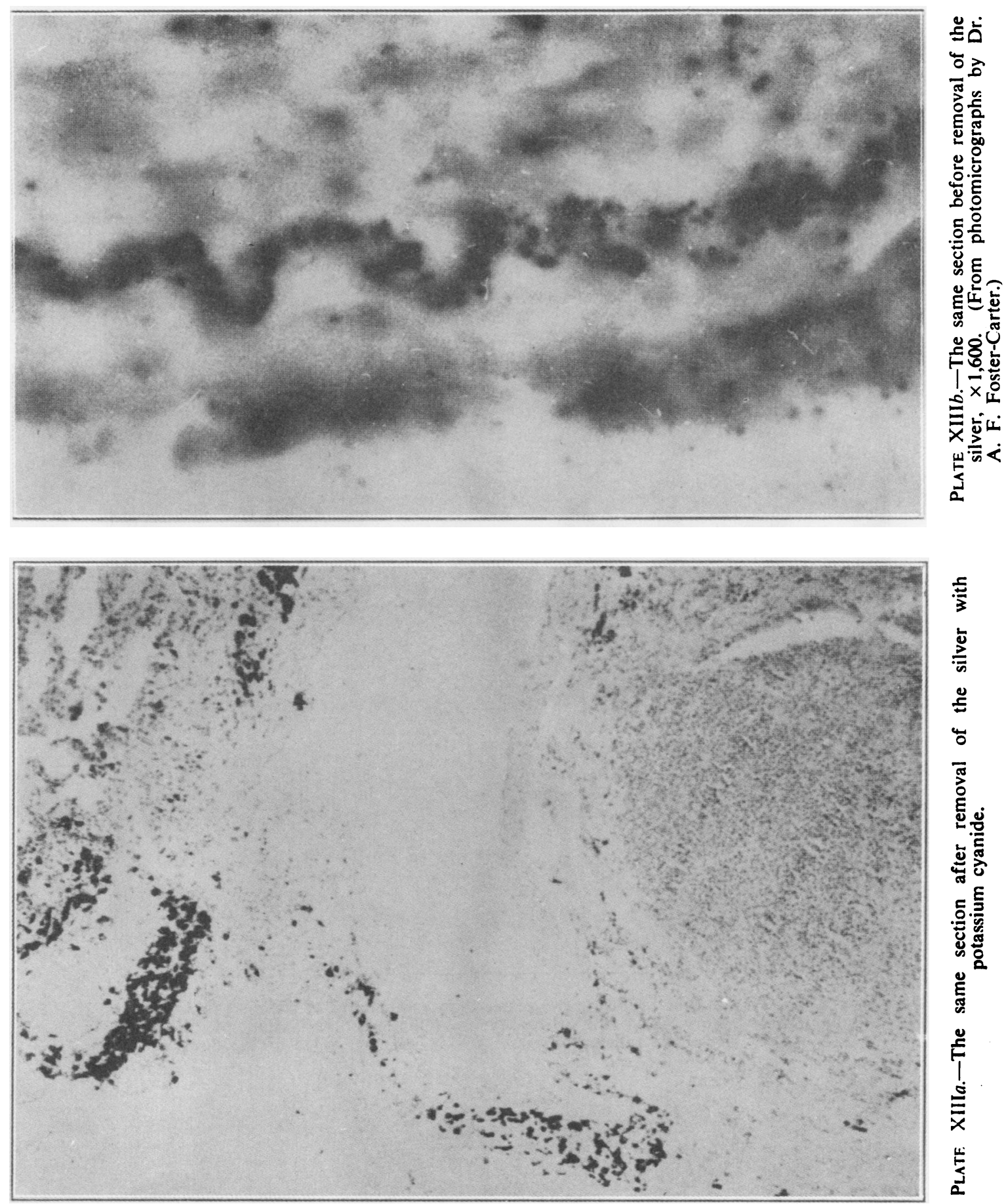


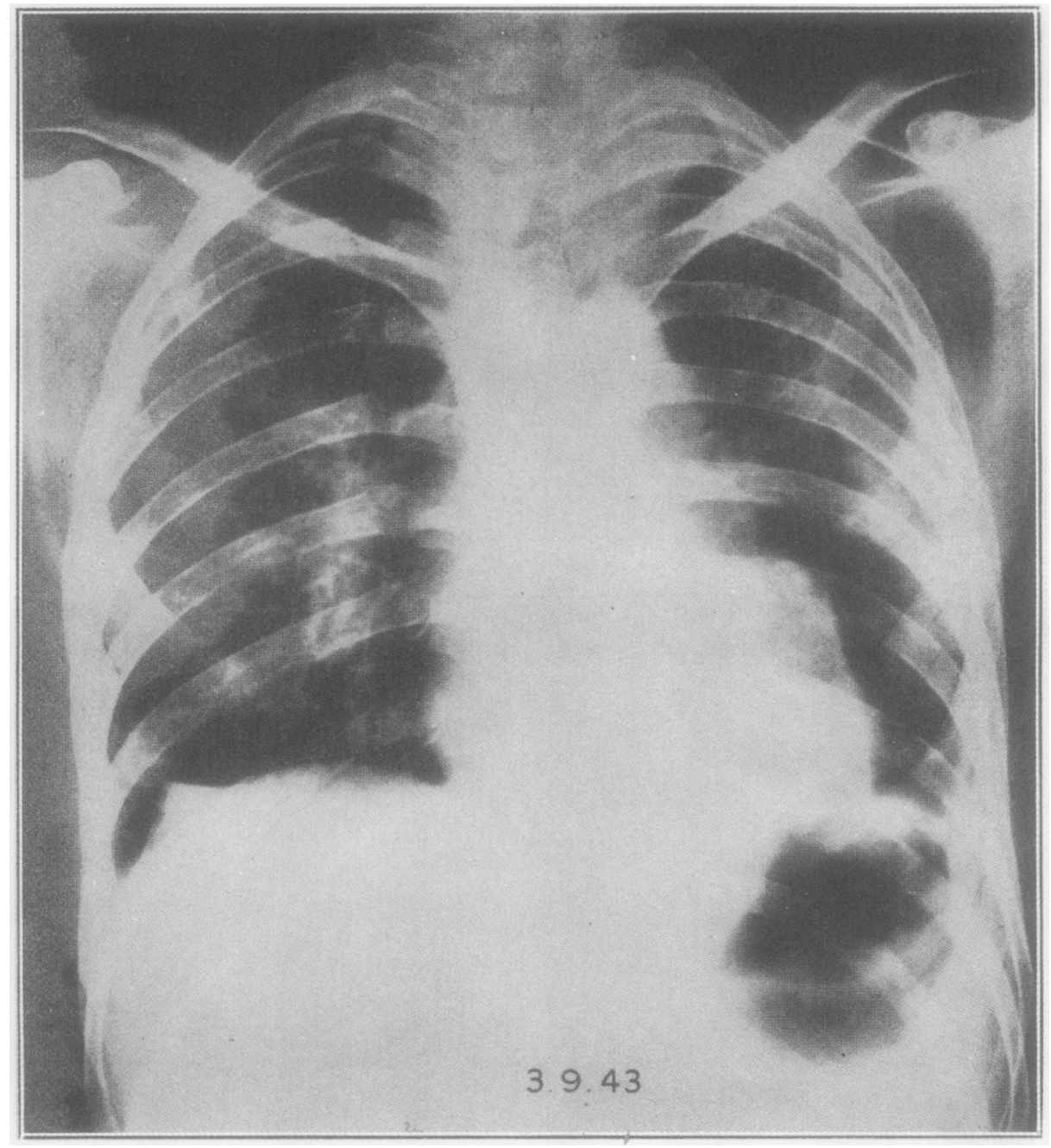

Plate XIV.-This and the following two plates show radiographs of stampers in a German aluminium factory in Frankfort-on-Main. (Obtained by Major M. Kennedy, R.A.M.C.) The above radiograph was taken in an early stage of the disease. 

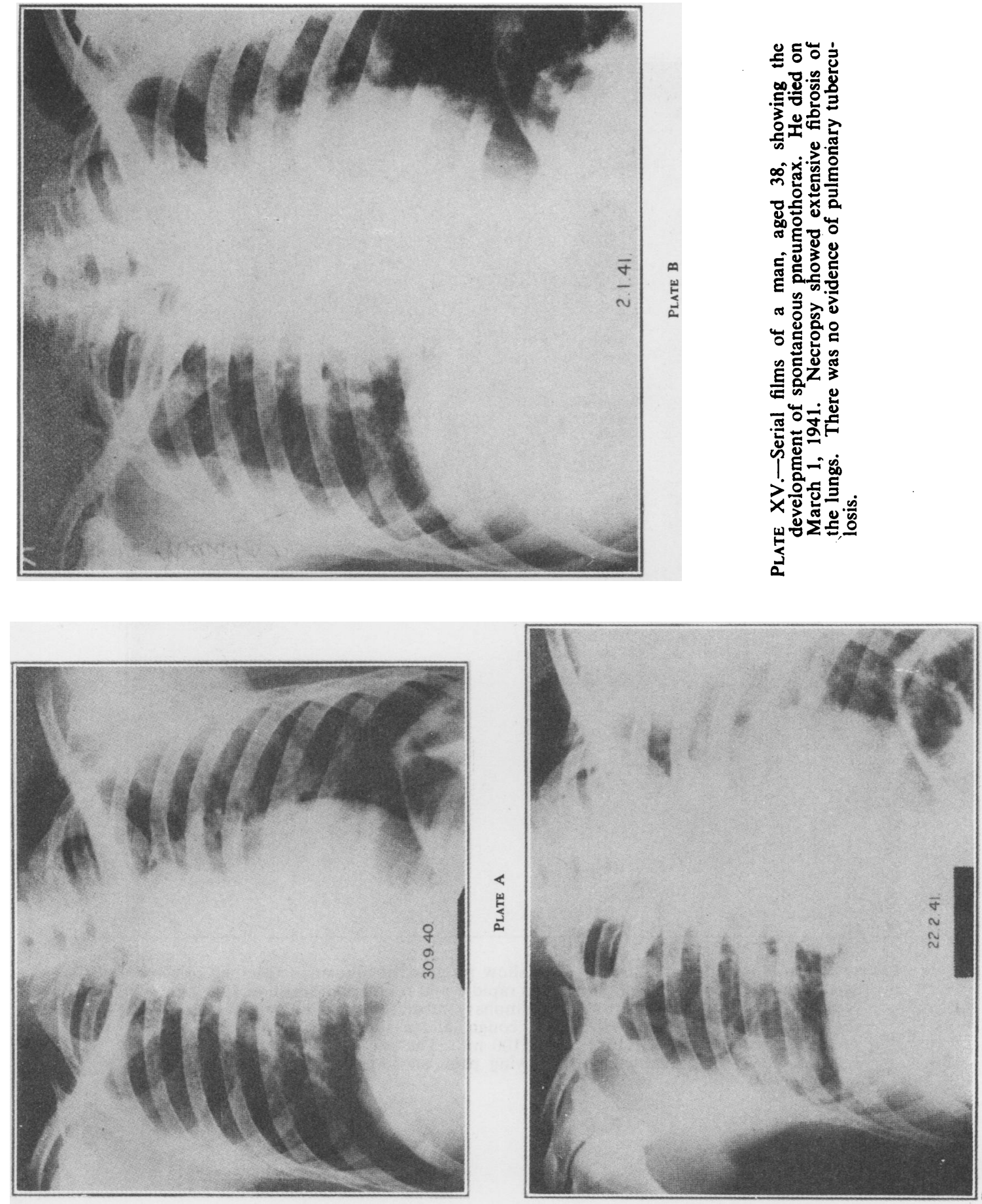

0 


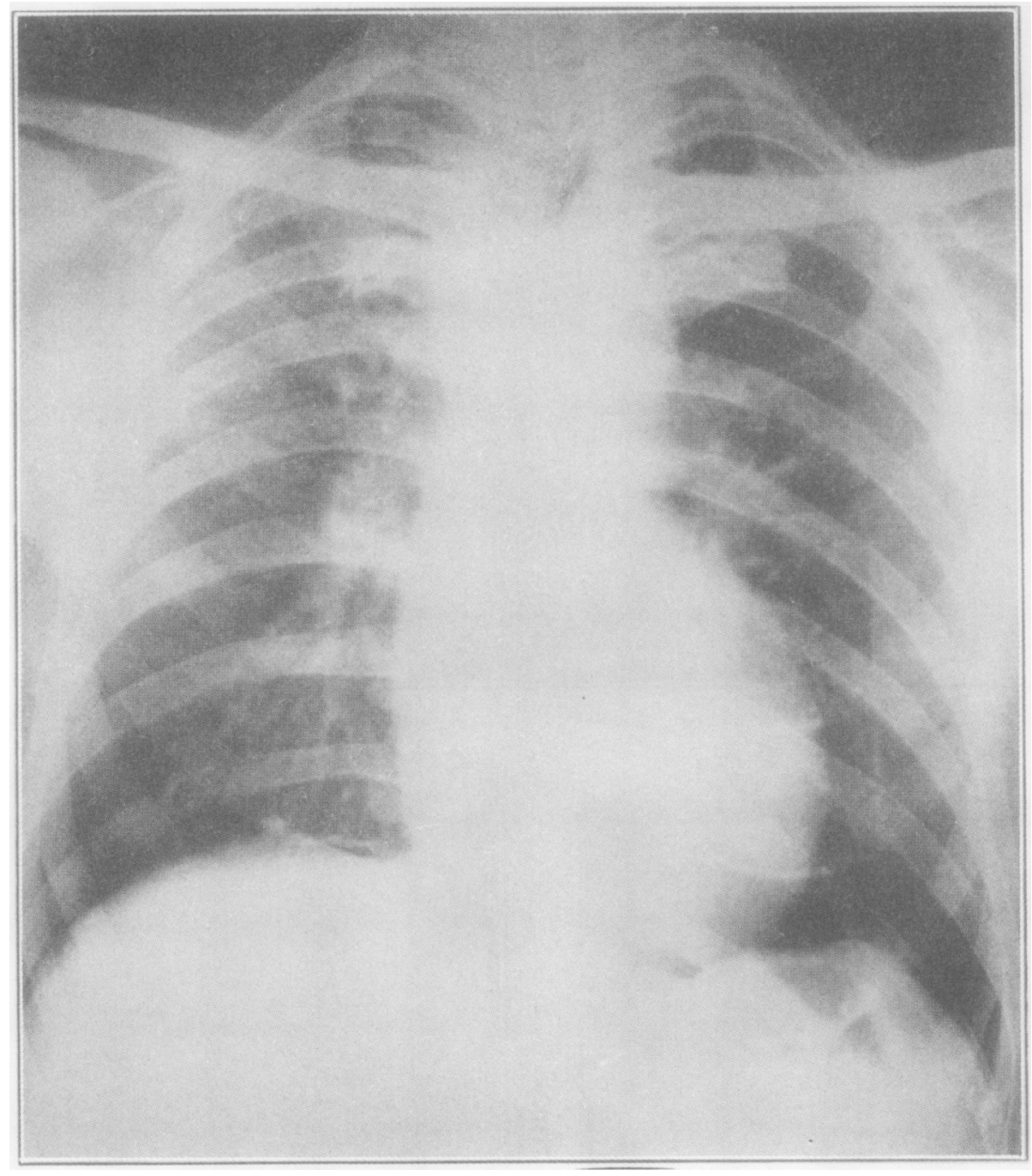

Plate XVI.-This and the following plate show progressive fibrosis in the lung in a man aged 46, in whom the disease progressed rapidly and resulted in death on July 25, 1944. Necropsy showed that there was no pulmonary tuberculosis. He complained of great shortness of breath, pain in the chest, cough, and a slight amount of sputum. His vital capacity on June 21,1943 , was $2,100 \mathrm{ml}$. The above radiograph was taken on Feb. 18, 1943, and those on the following page on June 2, 1944, and July 3, 1944, respectively. 


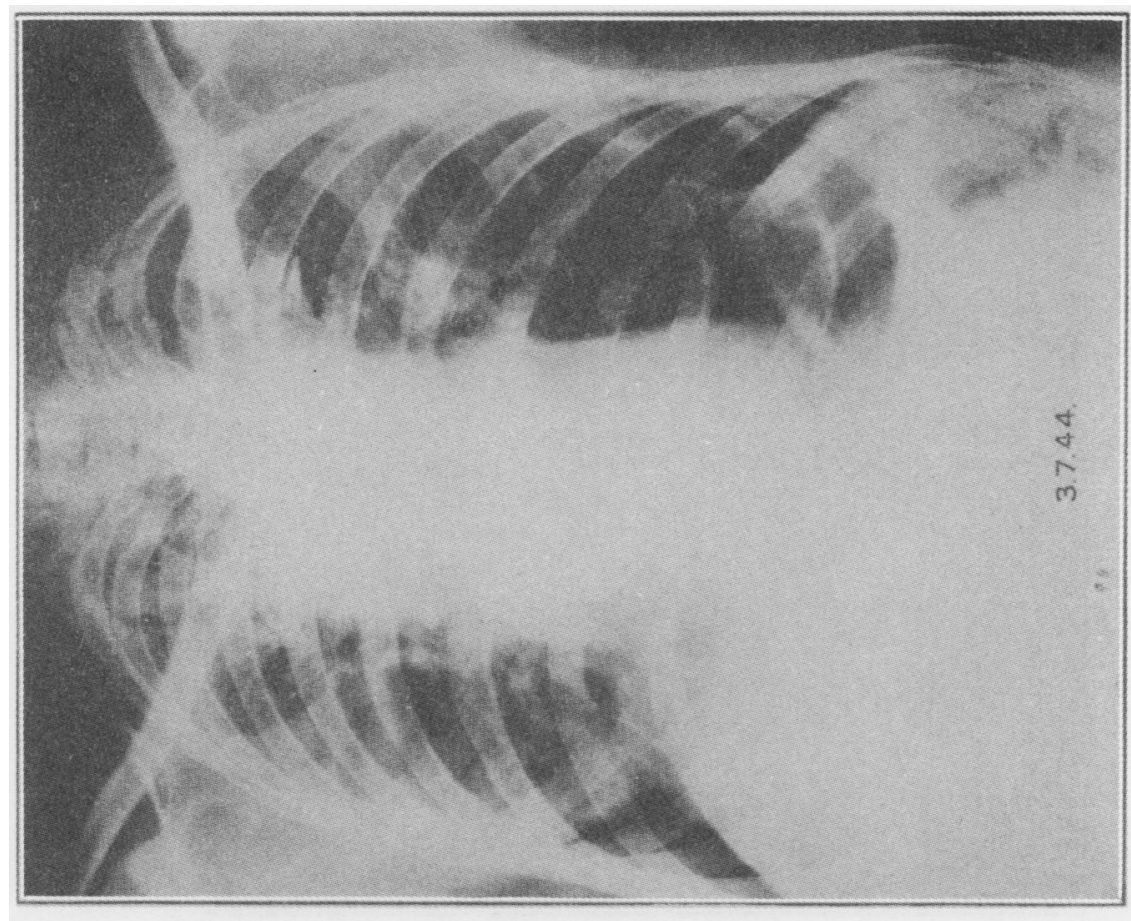

$\sum$
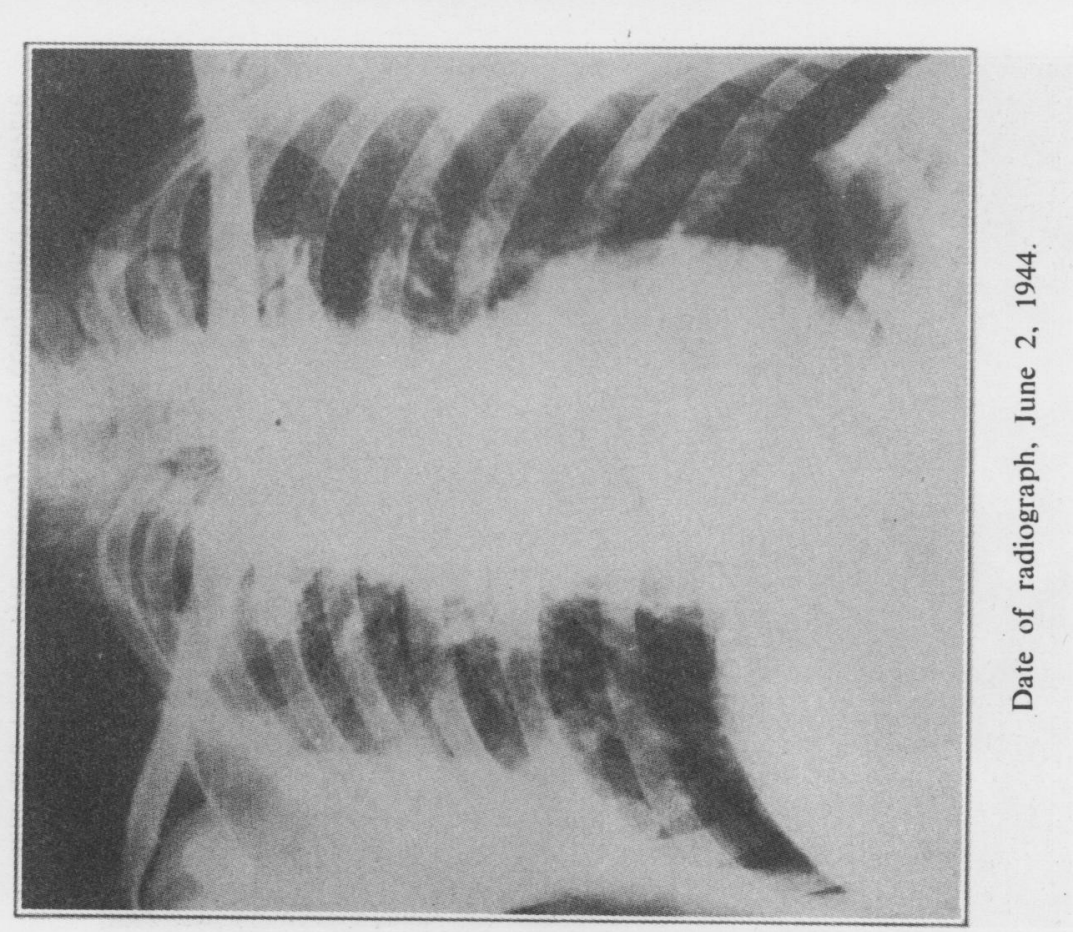

荘 

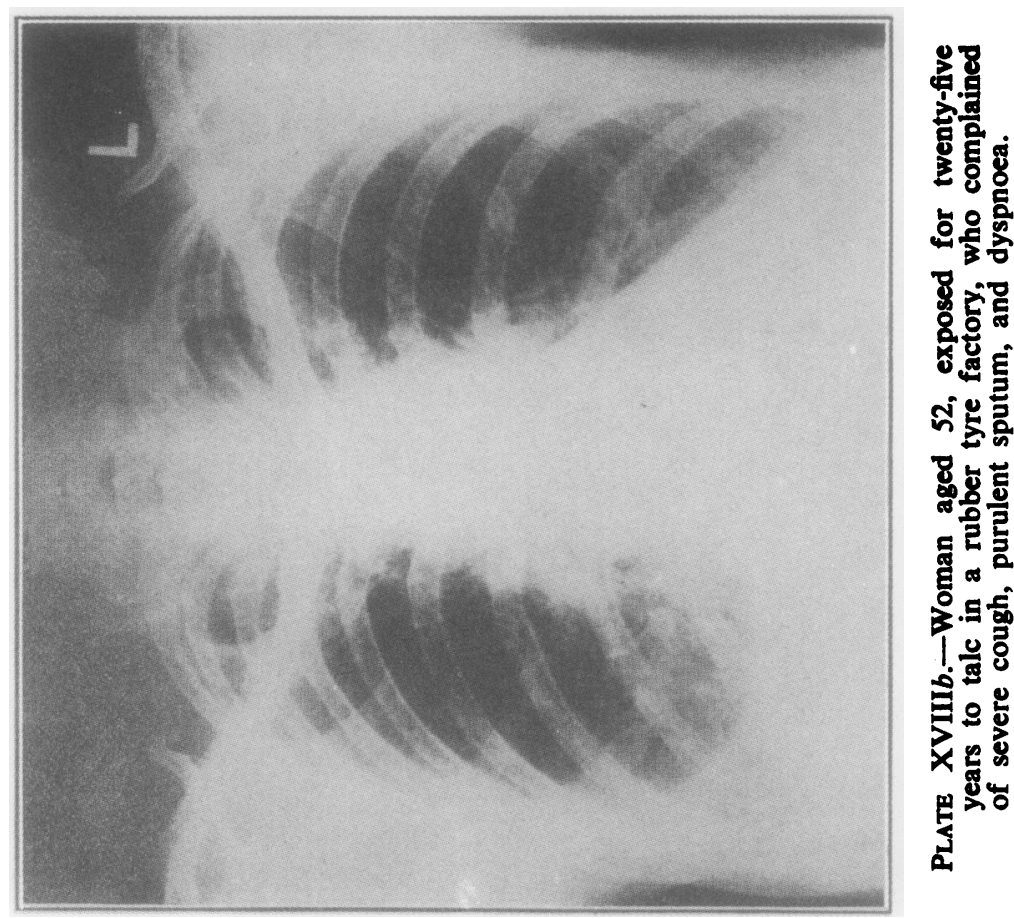

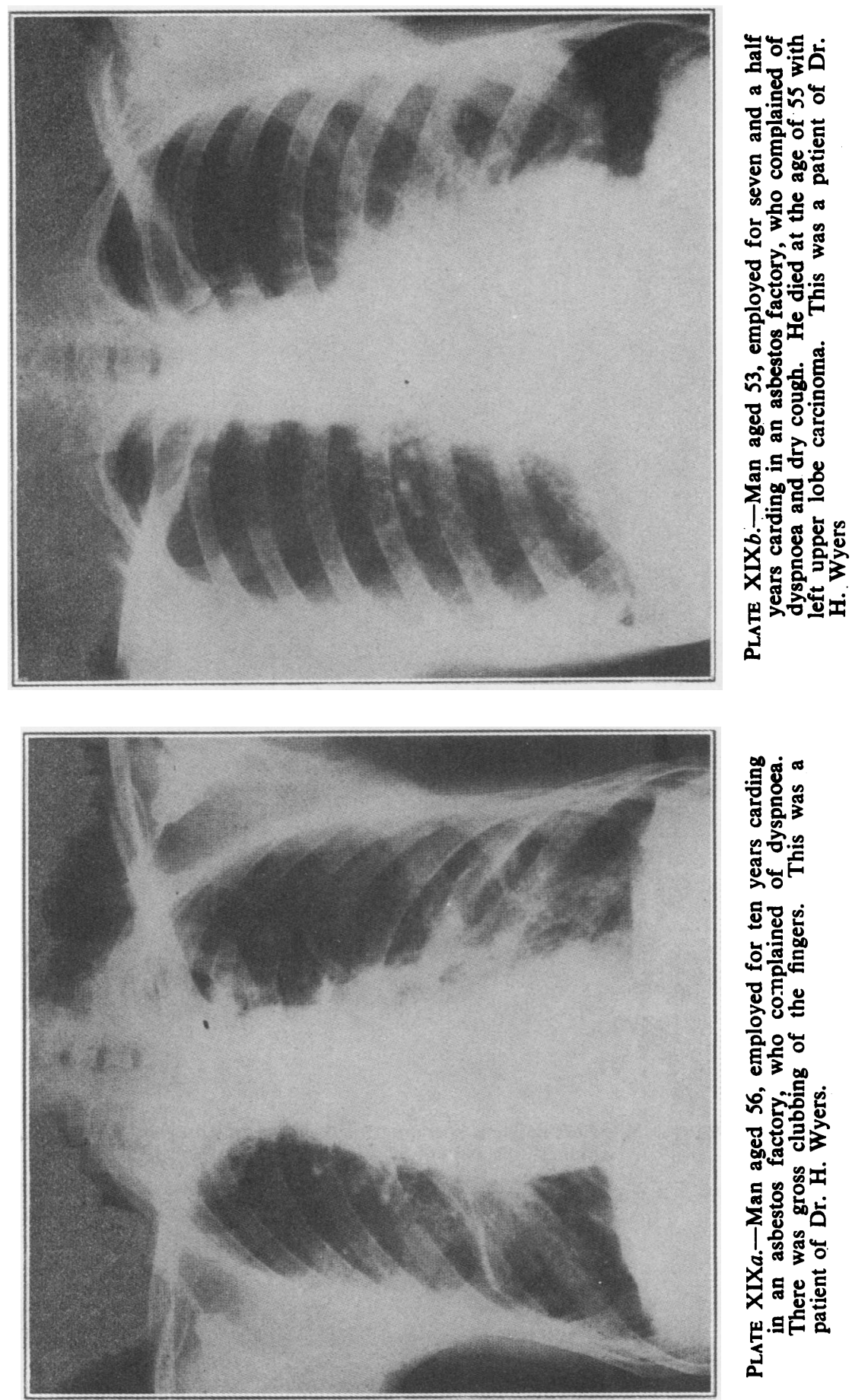


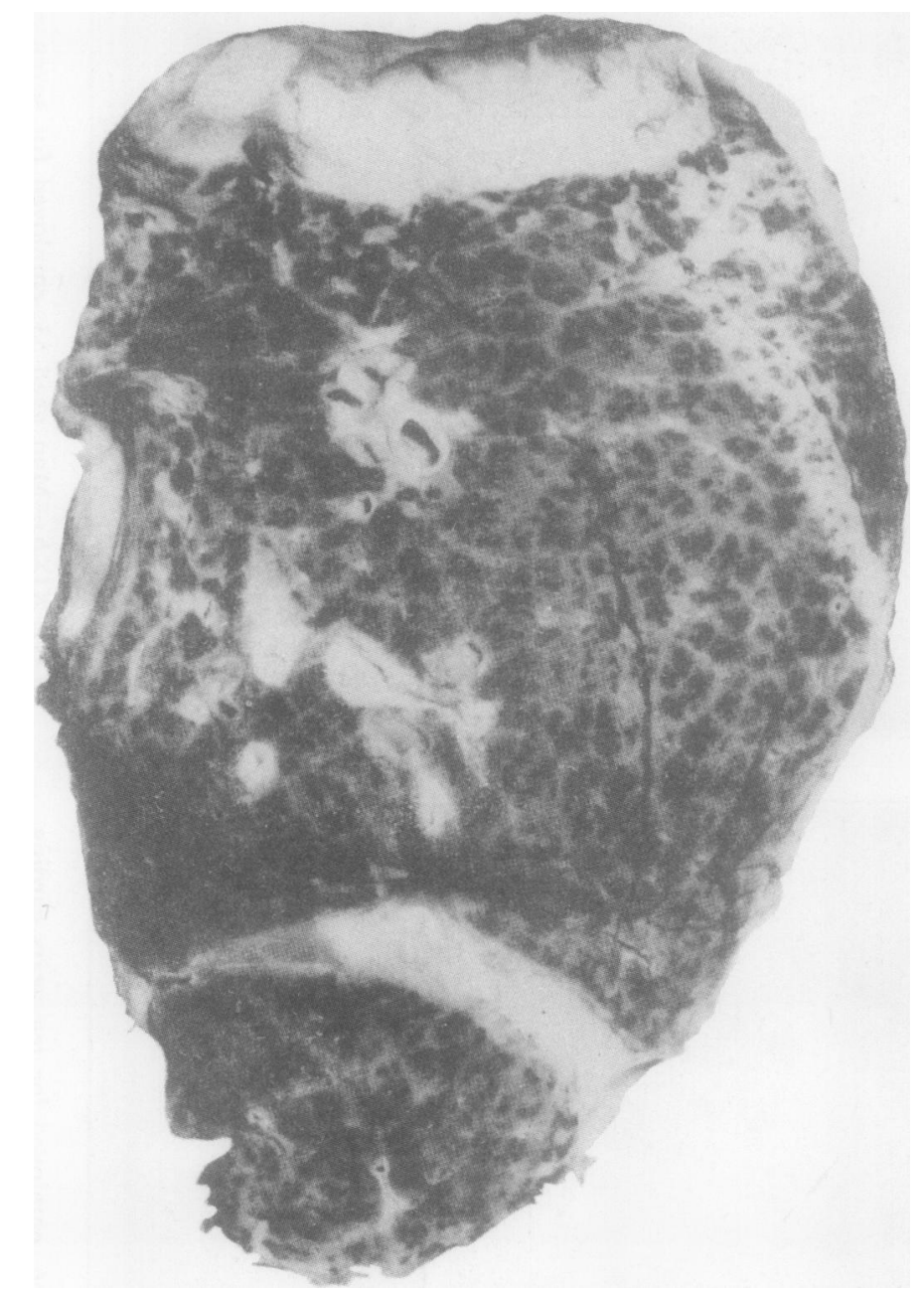

Plate XX.-Post-mortem specimen of the lung of an asbestos spinner. A patient of Dr. $H$. Wyers. 


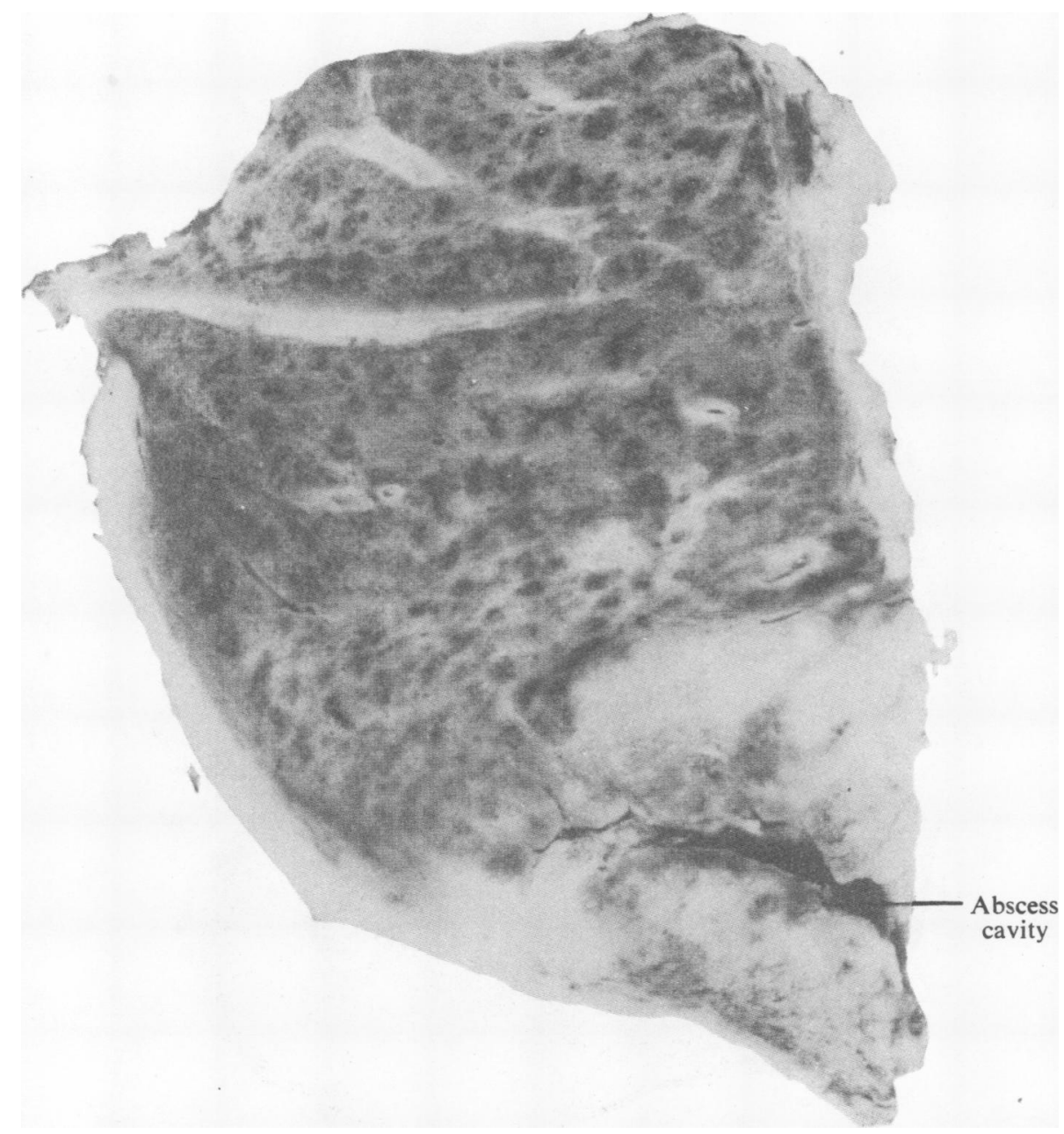

Plate XXI.-Post-mortem specimen of the lung of an asbestos worker, showing gross thickening of the pleura. The patient died of carcinoma of the bronchus with secondaries in the kidneys. A patient of Dr. H. Wyers. 


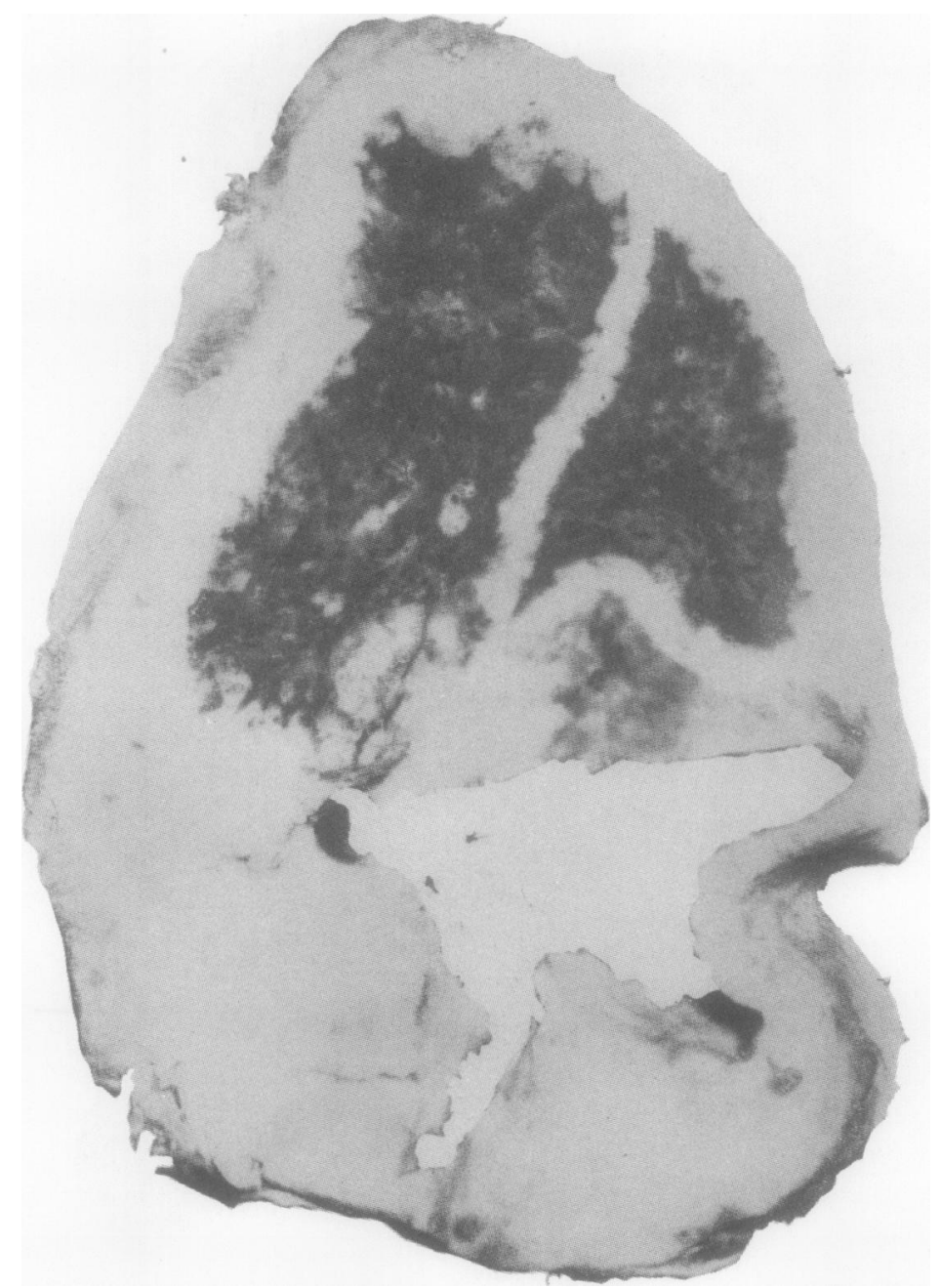

PLate XXII.-Post-mortem specimen of the lung of an asbestos worker. The patient died of endothelioma of the pleura. A patient of Dr. H. Wyers. 